\title{
The prevalence of Coxiella burnetii shedding in dairy goats at the time of parturition in an endemically infected enterprise and associated milk yield losses
}

\author{
José T. Canevari ${ }^{1,2^{*}}$ (D), Simon M. Firestone ${ }^{1}$, Gemma Vincent ${ }^{3}$, Angus Campbell ${ }^{1}$, Tabita Tan ${ }^{1}$, \\ Michael Muleme ${ }^{1}$, Alexander W. N. Cameron ${ }^{4}$ and Mark A. Stevenson ${ }^{1}$
}

\begin{abstract}
Background: This was a panel study of the prevalence of C. burnetii infection in does in an endemic dairy goat enterprise in Victoria, Australia. Our first objective was to determine the prevalence of does shedding C. burnetii at the time of parturition and to quantify the concentration of genome equivalents (GE) present in each C. burnetii positive sample. Our second objective was to determine the proportion of positive does that were persistent shedders. Our final objective was to quantify the association between C. burnetii qPCR status at the time of kidding and daily milk volumes produced during the subsequent lactation.

Results: Vaginal swabs $(n=490)$ were collected from does at the time of kidding and analysed using a quantitative polymerase chain reaction (qPCR) assay. Shedding of C. burnetii was detected in 15\% (95\% Cl: $12 \%$ to 18\%) of the sampled does. Does were classified as qPCR-negative, qPCR-positive low and qPCR-positive high based on the estimated concentration of GE from the qPCR. Persistent shedding at relatively low concentrations was detected in $20 \%$ (95\% Cl: 10\% to35\%) of shedding does sampled again at their subsequent parturition. After controlling for possible confounders and adjusting for variation in daily milk yields at the individual doe level, daily milk yields for qPCR-positive high does were reduced by $17 \%$ (95\% Cl: $3 \%$ to 32\%) compared to qPCR-negative does ( $p=0.02$ ).

Conclusions: Shedding concentrations of $C$. burnetii were highly skewed, with a relatively small group of does shedding relatively high quantities of $C$. burnetii. Further, high shedding does had reduced milk yields compared to qPCR-negative does. Early detection and culling of high shedding does would result in increased farm profitability and reduce the risk of $\mathrm{Q}$ fever transmission.
\end{abstract}

Keywords: Coxiella burnetii, Coxiellosis, Q fever, Dairy goats, Super shedders, Production losses, Australia

\section{Background}

$\mathrm{Q}$ fever is a zoonotic disease caused by the rickettsialike bacterium Coxiella burnetii. The microorganism occurs in two antigenic variations, phase I and phase II, which differ in the composition of membrane

\footnotetext{
${ }^{*}$ Correspondence: canevari.jose@inta.gob.ar

${ }^{1}$ Asia-Pacific Centre for Animal Health, Faculty of Veterinary and Agricultural Sciences, The University of Melbourne, Corner Park Drive and Flemington Road, 3010 Parkville Victoria, Australia

${ }^{2}$ Instituto de Investigación Animal del Chaco Semiárido, INTA, Leales, 4113 Tucumán, Argentina

Full list of author information is available at the end of the article
}

lipopolysaccharides [1]. Q fever affects a wide range of mammalian species among which domestic livestock constitute the main reservoir of infection for humans [2]. Once in the environment $C$. burnetii can survive for prolonged periods of time due to its capacity to differentiate into a spore-like form known as the small cell variant. In the acute phase, clinically infected humans may develop symptoms including high fever, headaches and joint and muscle pain [1]. Life-threatening persistent focalized $C$. burnetii infection(s), mainly endocarditis, can also occur in a relatively small percentage of cases [3]. Goats are frequently identified as a source of $\mathrm{Q}$ fever outbreaks in

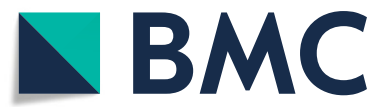

(c) The Author(s). 2018 Open Access This article is distributed under the terms of the Creative Commons Attribution 4.0 International License (http://creativecommons.org/licenses/by/4.0/), which permits unrestricted use, distribution, and reproduction in any medium, provided you give appropriate credit to the original author(s) and the source, provide a link to the Creative Commons license, and indicate if changes were made. The Creative Commons Public Domain Dedication waiver (http://creativecommons.org/publicdomain/zero/1.0/) applies to the data made available in this article, unless otherwise stated. 
humans [4, 5], as was the case in the outbreak of Q fever that occurred in The Netherlands in 2007 - 2010 where more than 4500 people were infected [6]. Goats are also the livestock species most likely to show clinical signs of disease, which include increased rates of abortion and an increase in the number of stillbirths and weak offspring [7]. An association between subclinical mastitis and $C$. burnetii infection has been reported in dairy cattle [8]. Also, puerperal C. burnetii vaginal shedder primiparous cows were found to yield less milk fat compared to negative cows [9]. While histopathological udder lesions have been found in goats artificially infected with $C$. burnetii [10], and an association has been detected between recent C. burnetii exposure and milk yield [11], we are aware of no studies that have been published investigating $C$. burnetii shedding at the time of kidding and its association with either subclinical or clinical mastitis or milk yield.

Infected goats can shed large quantities of $C$. burnetii into the environment at the time of parturition. Other documented shedding routes include the milk, feces, urine and saliva, though the amounts of bacteria shed via these routes is believed to be relatively low [12-15]. C. burnetii DNA can be detected in vaginal swabs using quantitative polymerase chain reaction (qPCR) techniques, making it possible to identify does that are shedding the infective agent at the time of kidding $[16,17]$. Also, qPCR can be used to monitor the presence of C. burnetii DNA in bulk tank milk [18-20]. Out of an array of available qPCR assays those targeting the com 1 gene and the insertion sequence IS1111 are the most frequently used [21]. qPCR assays targeting the com 1 gene have the advantage that the target gene occurs only once within the C. burnetii genome, making it possible to quantify the number of genome equivalents in a sample. Compared with the com 1 qPCR the IS1111 qPCR is more sensitive; an expected feature considering the insertion sequence it targets can occur up to 110 times within the C. burnetii genome [22-24]. Antibodies against C. burnetii can be assessed using a range of serological techniques of which the immunofluorescence assay (IFA) has the highest diagnostic sensitivity and specificity when used in goats [25].

Australia has one of the highest reported incidence rates of Q fever in humans with between 1.5 and 4.9 notified cases per 100,000 head of population at risk per year [26]. The frequency of $Q$ fever in humans in Victoria has historically been low compared with other states, with incidence rates ranging from 0.3 to 2.0 notified cases per 100,000 head of population at risk per year since 1991 [27, 28]. In 2012-2014 an outbreak of Q fever was associated with a large dairy goat enterprise in Victoria. A total of 24 people were infected; all of them farm staff with the exception of one individual who was a staff family member suspected as having acquired infection via contaminated fomites
[29]. Vaccination of all farm staff and elective vaccination of staff contacts with Q-VAX (the vaccine used to prevent $Q$ fever in humans in Australia) has, so far, prevented further human cases from occurring. Nevertheless, subsequent investigations carried out on this enterprise showed that coxiellosis was still prevalent among does and that C. burnetii DNA as well as specific antibodies to C. burnetii were present in bulk tank milk [11].

Long-term studies carried out in dairy cattle, sheep and goat farms where Q fever outbreaks have occurred have shown that infection can persist in herds-flocks for at least two years, with some animals shedding C. burnetii in two consecutive parturitions [30-33]. There have been few published reports describing the dynamics of infection in endemically infected herds-flocks. A better understanding of the stages of the production cycle when infection transmission risk is greatest and which age groups or stock classes are responsible for infection transmission provides essential information for the design of herd-flock level Q fever control and eradication strategies.

This was a panel study of the prevalence of $C$. burnetii in an intensively managed dairy goat enterprise related to a human outbreak [29] of Q fever in Victoria, Australia. There were three main objectives. Firstly, to retrieve vaginal swabs from does within 24 hours of kidding and to determine both the prevalence of does shedding $C$. burnetii and the concentration of genome equivalents (GE) present in each C. burnetiipositive sample. Our second objective was to select a subset of does identified as $C$. burnetii-positive at the first round of testing and to re-sample them at their subsequent kidding event to determine the proportion that were persistent $C$. burnetii shedders. Our final objective was to quantify the association between C. burnetii qPCR status at the time of kidding and both milk yields and somatic cell counts (SCCs) during the subsequent lactation. Results from qPCR testing of vaginal swab samples from aborted does submitted by farm staff were also included in this paper. Throughout this paper we use the nomenclature suggested by Lang (1990) [34] where the term coxiellosis is used to describe the presence of C. burnetii infection in animals and Q fever describes the clinical condition in humans.

\section{Results}

Does that had vaginal swabs positive for $C$. burnetii were present on all three sampled farms units in all kidding seasons with the exemption of Farm B in the March to April kidding season. Across the four kidding seasons and the three study farms there were 15 (95\% CI: 12 to 18) com 1 qPCR-positive does per 100 does at risk. The prevalence of shedding increased from the first to second parities and then decreased for does of parity three and above. Exceptions were the March to April kidding season 
when shedding was not detected in second parity does and the November to December kidding season when first parity does had a slightly higher prevalence than those in their second parity. When does were grouped by farm and parity the prevalence of shedding was stable over the four kidding seasons ranging from 13\% in the September to October season to $17 \%$ in the November to December season. For IFA serology the prevalence followed a similar pattern to that of qPCR though the decrease in seroprevalence for second to third parity does was less marked as the decrease in prevalence using the C. burnetii qPCR com1. When does were grouped by farm and parity the IFA seroprevalence ranged from 24 to $44 \%$ in the March to April and June to July kidding seasons, respectively (Table 1 ).

The distribution of C. burnetii GE concentrations in vaginal swabs was highly skewed. While the majority of does that were C. burnetii qPCR com1 positive shed relatively low quantities of bacteria, the concentration of a C. burnetii GE in a small number of does $(n=14)$ was above $>10^{3}$ and as high as $10^{9} \mathrm{GE}$ per $\mu \mathrm{L}$ of sample. There was a fair agreement between serology and shedding status after adjusting for bias (PABAK 0.37; 95\% CI: 0.28 to 0.45$)$. Nevertheless, 39 out of 71 does that were C. burnetii qPCR com 1 positive returned a negative result when tested with the IFA. The risk of a doe being IFA positive if she was shedding more than $10^{3} \mathrm{GE}$ per $\mu \mathrm{L}$ as measured by the qPCR com 1 assay was 2.6 (95\% CI 1.8 to 3.8) times the risk of a doe that was negative to the qPCR com1 assay (Table 2). Log10 transformed C. burnetii GE concentrations for does of parities 1, 2, 3 and $4+$ identified as positive were not statistically significantly different (Kruskall-Wallis test statistic 5.45; $p=0.14$ ).
Of the 40 does that were $C$. burnetii qPCR com 1 positive in 2016 and re-sampled when they kidded again in 2017, none were positive when tested with the $\operatorname{com} 1$ assay $(0 \%$; $95 \%$ CI $0 \%$ to $9 \%)$ whereas 8 (20\%; $95 \%$ CI: 10 to $35 \%)$ were positive when tested with the IS1111 assay. Out of the 26 vaginal swabs from aborted does submitted for com 1 qPCR testing, 14 (54\%; 95\% CI: $35 \%$ to $71 \%$ ) returned a positive result.

Mean daily milk volume yield for all does during the follow-up period (i.e. lactations starting with the kidding event at which does were sampled and up to 305 days in milk) was 3.03 (95\% CI: 3.02 to 3.04) litres. After adjusting for the effect of farm, season, parity and days in milk and using a random effect term at the individual doe level, does in the qPCR-positive high group produced 0.53 (95\% CI 0.08 to 0.98 ) litres less milk per day than does in the qPCR-negative group (Table 3). Daily milk yields for does in the qPCR-positive low group were similar to daily milk yields in the qPCR-negative group. No statistically significant association at the $p \leq 0.05$ level was found for qPCR status and SCC.

\section{Discussion}

The results of the present study show that under intensive management conditions coxiellosis in dairy goats can become endemic, with a relatively high prevalence of $C$. burnetii shedding does at parturition after several years from introduction of disease in the herd. Vaccination with a phase I vaccine is regarded as an effective control measure for C. burnetii infection in dairy goats [35]. However, no $\mathrm{Q}$ fever vaccines are licensed for use in animals in Australia. Efforts are currently underway to develop an autogenous vaccine to immunize animals in the enterprise

Table 1 Seroprevalence (IFA) and C. burnetii shedding prevalence assessed by qPCR in vaginal swabs (com 1) in recently kidded does on a large dairy goat enterprise in south western Victoria, Australia in 2016

\begin{tabular}{|c|c|c|c|c|c|c|c|c|c|}
\hline \multirow[t]{2}{*}{ Kidding season } & \multirow[t]{2}{*}{ Assay } & \multicolumn{4}{|c|}{ Does positive / total sampled } & \multicolumn{4}{|c|}{ Prevalence as no. of positive does per 100 does at risk $(95 \% \mathrm{Cl})$} \\
\hline & & Farm A & Farm B & Farm C & Total & Farm A & Farm B & Farm C & Total \\
\hline March to April & coml & $0 / 34$ & $11 / 33$ & $1 / 22$ & $12 / 89$ & $0(0,10)$ & $33(20,50)$ & $4(1,22)$ & $13.5(7.9,22.1)$ \\
\hline June to July & coml & $16 / 41$ & $4 / 55$ & $2 / 51$ & $22 / 147$ & $39(26,54)$ & $7(3,17)$ & $4(1,13)$ & $15(10.1,21.6)$ \\
\hline September to October & coml & $15 / 52$ & $2 / 40$ & $1 / 42$ & $18 / 134$ & $29(18,42)$ & $5(1,16)$ & $2(0,12)$ & $13.4(8.7,20.2)$ \\
\hline November to December & coml & $17 / 41$ & $2 / 40$ & $2 / 39$ & $21 / 120$ & $41(28,57)$ & $5(1,16)$ & $5(1.17)$ & $17.5(11.7,25.3)$ \\
\hline March to April & IFA & $13 / 34$ & $15 / 33$ & $11 / 22$ & $39 / 89$ & $38(24,55)$ & $45(30,62)$ & $50(31,69)$ & $28.3(21.4,36.3)$ \\
\hline June to July & IFA & $9 / 40$ & $9 / 55$ & $17 / 51$ & $35 / 146$ & $22(12,37)$ & $16(9,28)$ & $33(22,47)$ & $24(17.8,31.5)$ \\
\hline September to October & IFA & $9 / 51$ & $13 / 39$ & $9 / 41$ & $31 / 131$ & $18(10,30)$ & $33(21,49)$ & $22(12,37)$ & $23.7(17.2,31.6)$ \\
\hline November to December & IFA & $18 / 41$ & $13 / 40$ & 9/39 & $40 / 120$ & $18(10,30)$ & $32(20,48)$ & $23(13,38)$ & \\
\hline \multicolumn{10}{|l|}{$33.3(25.5,42.2)$} \\
\hline \multirow[t]{2}{*}{ Total } & coml & $48 / 168$ & $19 / 168$ & $6 / 154$ & $73 / 490$ & $29(22,36)$ & $11(7,17)$ & $4(2,8)$ & $14.9(12,18.33)$ \\
\hline & IFA & $49 / 166$ & $49 / 166$ & $46 / 153$ & $145 / 486$ & $29(23,37)$ & $30(23,37)$ & $30(23,38)$ & $29.8(25.9,34)$ \\
\hline
\end{tabular}


Table 2 Levels of shedding (GE/ $\mu \mathrm{L}$ )determined by qPCR com 1 assay and serological status (IFA) in an endemically infected dairy goat enterprise in Victoria, Australia

\begin{tabular}{|c|c|c|c|c|c|}
\hline \multirow{2}{*}{$\begin{array}{l}\text { Shedding level } \\
\text { (GE per } \mu \mathrm{L})\end{array}$} & \multicolumn{4}{|c|}{ Term kidders } & \multirow{2}{*}{$\frac{\text { Aborted goats }^{a}}{\text { Total }}$} \\
\hline & $\mathrm{IFA}+$ & IFA - & IFA missing & Total & \\
\hline Negative & 113 & 302 & 2 & 417 & 12 \\
\hline $1-10^{3}$ & 22 & 35 & 2 & 59 & 4 \\
\hline$>10^{3}$ & 10 & 4 & - & 14 & 10 \\
\hline Total & 145 & 341 & 4 & 490 & 26 \\
\hline
\end{tabular}

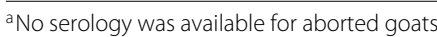
$\mathrm{GE}=$ genome equivalents

Table 3 Australia in 2016. Multiple linear regression model outputs of factors influencing daily milk yields in does on a large dairy goat enterprise in south western Victoria

\begin{tabular}{lllll}
\hline Variable & \multicolumn{1}{l}{ Coefficient (SE) $t$} & $p$ value & $95 \% \mathrm{Cl}$ \\
\hline Intercept & $2.38(0.11)$ & 21.26 & $<0.001$ & 2.15 to 2.59 \\
qPCR status: & & & - \\
$\quad$ Negative & Reference & - & - \\
Positive low & $-0.08(0.12)$ & -0.68 & 0.495 & -0.33 to 0.16 \\
Positive high & $-0.53(0.23)$ & -2.33 & 0.02 & -0.98 to $-0.08{ }^{a}$ \\
Parity: & & & & \\
1 & Reference & & - & - \\
2 & $0.34(0.10)$ & 7.29 & $<0.001$ & 0.54 to 0.94 \\
3 & $1.22(0.11)$ & $10.7<0.001$ & 0.99 to 1.44 \\
$4+$ & $0.71(0.13)$ & 5.5 & $<0.001$ & 0.46 to 0.96
\end{tabular}

Kidding season:

March to April Reference

$\begin{array}{lllll}\text { June to July } & 0.06(0.11) & 0.49 & 0.62 & -0.17 \text { to } 0.28\end{array}$

September to October $\quad 0.53(0.12) \quad 4.52<0.001 \quad 0.3$ to 0.77

November to December $0.54(0.12) \quad 4.57<0.0010 .3$ to 0.77

Farm:

A Reference

$\begin{array}{lllll}\text { B } & 0.24(0.10) & 2.34 & 0.02 & 0.04 \text { to } 0.44\end{array}$

C $\quad-0.71(0.11) \quad-6.72<0.001-0.92$ to -0.5

Random effect SD

Goat id 0.82

Within goat temporal correlation with first order autoregressive structure (AR1): 0.23

AIC: 343081.1

a Interpretation: After adjusting for the effect of parity, kidding season, days in milk and farm, daily milk yields from does that were qPCR-positive high were 530 (95\% Cl 80 to 980 ) $\mathrm{mL}$ less than does that were qPCR negative. The random effect at the goat level accounts for repeated measures and individual animal variability. SE: standard error

Cl: confidence interval where the present study was carried out. A study by Astobiza et al. (2010) [36] showed treatment of pregnant sheep with oxytetracycline did not reduce the risk of $C$. burnetii shedding at lambing. The impact of changes in management practices (like the use of prolonged lactations to reduce the number of kidding events per year) on disease transmission have been modeled by Bontje et al. [37]. Predictions from this model suggest that while these interventions can lead to a reduction in the amount of environmental contamination, they alone are not sufficient to allow the disease to be eradicated. While the study of Bontje et al. [37] provides useful insights into the effectiveness of coxiellosis control methods in a European herd management context, its ability to be applied to Australian dairy goat management conditions is limited mainly due to the complex seasonal kidding patterns that are feature of intensively managed dairy goat herds in Australia. There is a clear need for herd-flock managers to have access to tools and/or management strategies to allow coxiellosis to be controlled and/or eradicated in livestock farms in Australia. Ideally, the relative efficacy of recommended tools should be based on empirical evidence. The results presented in this paper partially address this need.

Our results show that while most qPCR-positive does shed relatively low concentrations of $C$. burnetii in their vaginal fluids at the time of parturition, a small proportion shed very high concentrations. Interestingly, the small proportion of does that were shedding high concentrations of C. burnetii (which we term 'super shedders') shed similar concentrations to does that had aborted. The phenomenon of super shedders has previously been described for coxiellosis as well as for other infectious diseases of livestock. In Germany, a single C. burnetii super-shedding ewe that lambed in a farmers' market was the source of a Q fever outbreak that resulted in 299 infected people [38]. Capparelli et al. [39], studied Brucella abortus shedding patterns in the milk of water buffaloes and found that while the majority of Brucella abortus-positive buffalo were shedding low concentrations of bacterium a small proportion shed very high concentrations. Similar findings were reported by Omisakin et al. [40] in a study of Escherichia coli $\mathrm{O} 157$ in cattle in the United Kingdom. In their cross-sectional study Omisakin et al. estimated that approximately 97\% of Escherichia coli O157 recovered from the environment was attributable to $9 \%$ of animals that were shedding.

In a cross-sectional study following an outbreak of coxiellosis in goats in France de Cremoux et al. [41] quantified the number of $C$. burnetii GE recovered in vaginal swabs in recently kidded does using the $I S 1111$ assay. de Cremoux et al. [41] showed that between $6 \%$ and $33 \%$ of does across three flocks were high shedders (greater than $10^{6}$ bacteria per swab). While the findings of de Cremoux et al. 
are not directly comparable with ours because GEs were estimated using a different assay and results were reported as absolute GE counts (as opposed to concentrations), it is evident that in both studies the distribution of GE estimates is skewed, meaning that while most qPCR-positive does shed small amounts of $C$. burnetii, a substantially smaller fraction shed large amounts. If does contributing to the majority of environmental contamination can be identified and culled before either aborting or kidding this could have a major impact on reducing the level of environmental contamination and the probability of disease transmission.

While super shedders are likely to play an important role in the transmission of disease, persistent shedders can perpetuate coxiellosis transmission. Of the 40 does that tested positive to $\operatorname{com} 1$ in 2016 and were tested again in 2017, all were negative to the com 1 assay and $20 \%$ $(n=8)$ were positive to the IS1111 assay. Due to the superior sensitivity of the IS1111 assay compared with the com1 assay our inference is that the level of shedding in the persistently shedding group of does was low. Berri et al. (2005) [42] conducted a longitudinal study in a goat herd in France that had experienced an abortion outbreak due to coxiellosis and found no PCR positives in vaginal swabs when does were sampled at the subsequent kidding season. This finding led the authors to hypothesize that C. burnetii shedding by infected does was limited to one parturition. We note however, that vaginal swabs in that study were obtained two weeks after parturition, which could have markedly reduced the likelihood of detecting C. burnetii shedding does. Later, in an investigation of an outbreak of abortions in another dairy goat herd in France, Berri et al. (2007) [31] found that $26 \%$ of the does that were C. burnetii shedders at the time of kidding had also been shedders at their previous kidding. C. burnetii GE concentrations for the repeat-shedding does were not reported. In our study we show that infected does can shed C. burnetii over at least two consecutive parturitions. A weakness of previously published research in this area has been that the change in C. burnetii infection status of individual does from one parturition to the next has not been unambiguously reported. Instead, authors have simply documented the group-level prevalence of $C$. burnetii for groups of consecutively kidding does. This approach is likely to misrepresent the true proportion of does that are persistent shedders due to (among other factors) individual herd replacement and culling rates. We conclude that if one was attempting to eradicate $Q$ fever from a dairy goat herd, priority should be placed on identifying and isolating high shedders as opposed to identifying and removing persistently shedding does. Our reasoning for this is two-fold. Firstly, the proportion of persistently shedding does is relatively small and secondly the quantities of $C$. burnetii shed by persistently shedding does is relatively small. Our results show that for monitoring purposes the $I S 1111$ assay is preferred over the com 1 assay due to its superior sensitivity for detecting relatively low levels of C. burnetii DNA.

Does presented for sampling were those that had kidded during the previous 24 hours. Due to logistic limitations we were unable to determine the exact time of kidding for each doe. For this reason it is possible that detected differences in C. burnetii shedding quantities were influenced by the interval from kidding to the time of sampling, with higher concentrations of $C$. burnetii likely to be shed closer to the time of delivery, leading to missclassification of individual doe qPCR category assignment. An argument against this explanation is the negative association between daily milk yields for C. burnetii qPCR-positive high does as discussed below. Abortion rates reported by the herd managers in this enterprise ranged from 2 to $8 \%$ across the three farms and four kidding seasons. It cannot be ruled out that abortion causes other than coxiellosis also played a role in fetal loss in these herds. Throughout 2016-2017 14 vaginal swab samples from the 26 does that aborted returned a $\mathrm{qPCR}$ com1 positive result. The concentration of C. burnetii GE found in positive samples from aborted does was high (Table 2) and similar to those found in a prospective study of sheep and goat abortion cases in Ontario, Canada [43]. An area of interest for future work on this farm would be to investigate abortion causes and the extent to which coxiellosis alone, or in combination with, other abortion-causing agents is responsible for reproductive losses.

The agreement between serology and $\mathrm{qPCR}$ was not substantial, which is consistent with findings from other studies [41, 44-46]. However, the agreement improved in does that were shedding high concentrations of $C$. burnetii (Table 2). Out of the 14 goats shedding above $10^{3}$ $\mathrm{GE} / \mu \mathrm{L}, 10$ had a positive result to IFA. The reasonably strong agreement between qPCR and serology for high shedder does indicates that there may be some use for serology as a means for detecting high shedder does in endemically infected herds. We note that in the present study vaginal swabs and blood samples were collected at the same time (within 24 hours after kidding) hence it cannot be assumed that high shedders could actually be detected using serology before kidding. A useful area of future research would be to collect blood samples for IFA serology from does entering their last third of gestation and to compare the IFA results to qPCR com 1 results from vaginal swabs taken at the time of kidding. Detection of C. burnetii in whole blood samples by qPCR is a possible alternative to serology for this purpose, which could have the additional benefit of being a method for detecting super shedders in vaccinated herds.

With regards to the impact of $C$. burnetii infection on milk yield we identified that daily milk volume yields 
were lower in does that comprised the qPCR-positive high group compared with qPCR-negative does. Given average daily milk yields in these herds were in the order of 3 litres, our inference is that $C$. burnetii infection in the relatively small proportion of does classed as high shedders results in a substantial (i.e. 3 to $32 \%$ ) reduction in daily milk yields. In a study that assessed seroconversion dynamics at the time of kidding Muleme et al. [11] found that does that had seroconverted to phase I IgG produced $0.2 \mathrm{~L}$ of milk per day more than does with no protective antibody response in the first 9 weeks of lactation. We hypothesize these results represent two sides of the same coin, the drop in milk yields associated with $C$. burnetii infection found in the present study relates to the gain in daily milk yields observed by Muleme et al. in does with a protective immune response. Infection with $C$. burnetii in goats can lead to placentitis, endometritis and mild lesions in the mammary gland [10], and these conditions provide plausible biological explanations for the milk losses identified in this study. In cows, Barlow et al. [8] found an association between the presence of $C$. burnetii in individual milk samples and increased SCCs. In the present study, no statistically significant association between individual SCCs and C. burnetii qPCR results in vaginal swabs was found. We note, however, that only one individual SCC estimate was available per doe per lactation. Testing for presence of C. burnetii in individual milk samples, as opposed to vaginal swabs, and controlling for presence of most common microorganisms that cause mastitis in goats would be a more appropriate way of addressing the question on whether $C$. burnetii can cause subclinical mastitis in goats. This is the first time a negative association between $C$. burnetii infection status and milk yield in dairy goats has been reported.

\section{Conclusions}

Shedding concentrations of $C$. burnetii were highly skewed, with a relatively small group of does shedding relatively high quantities of $C$. burnetii. Further, high shedding does had reduced milk yields compared to qPCRnegative does. Agreement between serology and shedding status was improved in does shedding high concentrations of $C$. burnetii. Future studies should aim at developing improved methods for early detection of high shedding does. Eradication of $C$. burnetii from intensively managed dairy goat herds should have a positive impact on herd profitability (in terms of increasing daily milk yields) as well as reducing the likelihood of dairy goats being a source of C. burnetii infection for humans.

\section{Methods}

\section{Study design and study population}

The source population for this study were does on three of the four farm units that comprise a large dairy goat enterprise in south western Victoria, Australia. The eligible population were does that kidded during the period 1 March to 31 December 2016. At the start of the study there were up to 1500 does milking in each of the three study herds. The majority of does in each herd were Saanen with smaller numbers of Toggenburgs and Alpines. Does were housed in sheds using a deep litter system and fed a mixture of concentrates and roughages ad libitum throughout the lactation. In each of the herds mating was timed so that does kidded in four batches throughout the year (March to April, June to July, September to October and November to December). Each herd was visited once weekly during each of the four kidding seasons and vaginal swab and whole blood samples were taken from each doe that had kidded during the previous $24 \mathrm{~h}$, leading to a total of 490 samples from full-term kidding does. A subsample of does $(n=40)$ identifed as $C$. burnetii-positive from the 2016 sampling had vaginal swabs taken again at their subsequent kidding event in 2017. Throughout 2016 and 2017, an additional 26 vaginal swabs from aborted does were obtained by farm staff and submitted for qPCR com1 testing. The volume of milk produced by each doe for each day of lactation was measured and recorded using the milking machine used on each farm. Individual doe milk samples were collected on four occasions throughout the year and submitted for individual doe somatic cell count estimation. These details were collated with each doe's biographical data, with most of the does included in the study having at least one SCC estimate. Biographical data for each doe, the dates of sample collection and the results of vaginal swab and blood tests were stored in a relational database.

DNA from each of the vaginal swab samples was extracted using a HiYield Genomic DNA Mini Kit (Real Biotech Corporation) according to the manufacturer's instructions. Real time PCR analyses targeting the com 1 gene were carried out using the methodology described by Lockhart et al. (2011) [47]. The number of C. burnetii GE per $\mu \mathrm{L}$ of sample was estimated using a standard curve described by Muleme et al. (2017) [48]. Vaginal swabs from the 40 does identified as positive to the com 1 qPCR in 2016 and resampled in 2017 were tested using both the com1 and IS1111 qPCR. The IS1111 qPCR assay was carried out following the methodology described in [49]. Only samples presenting the typical amplification curve and with a Ct (cycle threshold) value below 40 were considered positive. High-pure water served as the negative control for the qPCR assays. The com 1 amplicon cloned into a plasmid and DNA extracted from Vero cell cultures of C. burnetii Nine Mile RSA439 (Phase II, Clone 4) were used as positive controls for the com1 and IS1111 assays, respectively. Serological testing was carried out using the methods described by [25] using a 1/160 dilution cutoff. For IFA negative controls serum from New Zealand 
goats (a country declared free of $C$. burnetii by the World Organisation for Animal Health) was used. Serum samples from two goats from a known C. burnetii-positive farm that tested positive to the complement fixation test (CFT) were used as IFA positive controls.

\section{Statistical analyses \\ Impact of qPCR status on daily milk yields}

Individual daily milk volume records of up to 305 days in milk were available for 462 of the 490 does sampled in $2016(n=110,024$ records in total). Daily milk volumes greater than 15 litres $(n=311)$ were deemed implausible and were discarded from the analyses. Does were grouped into three categories based on the estimated concentrations of $C$. burnetii present in their vaginal swab samples. The number of $C$. burnetii GE per $\mu \mathrm{L}$ present in each qPCR-positive vaginal swab sample was plotted as a frequency histogram. Does shedding C. burnetii concentrations greater than the third quartile plus 1.5 times the interquartile range (i.e. outliers) comprised the first group $(n=14)$. Does shedding less than this threshold comprised the second group $(n=56)$, and those that were $C$. burnetii-negative comprised the third group $(n=392)$. In the remainder of this paper we use the terms qPCR-positive high, qPCR-positive low, and qPCRnegative (respectively) to refer to does in each of these categories. The mean $\mathrm{Ct}$ values for groups qPCR-positive low and qPCR-positive high were 34.9 (95\% CI: 34.1 to 35.6) and 23.9 (95\% CI: 19.7 to 28.2), respectively. To compare daily milk yields in the first 305 days of lactation among the three C. burnetii qPCR com1 status groups a generalized additive mixed-effects model was developed. Parity, kidding season, farm and days in milk were included as fixed effect terms in the model to adjust for their potentially confounding effect on daily milk yield. A penalized spline term was used to account for the non-linear association between days in milk and daily milk yield. Lack of independence in the data arising from repeated measurements of milk yield for each doe were accounted-for by including a random effect term at the individual doe level. Several options for covariance structure of the random effect term were tested and compared using the Akaike Information Criterion (AIC), and the best fitting of these, a first order autoregressive (AR1) covariance structure was used to account for autocorrelation of error terms [50]. The final model was of the form:

$$
\begin{aligned}
& M Y_{i j}= \beta_{0}+\beta_{1} \text { Status }_{i}+\beta_{2} \text { Parity }_{i}+\beta_{3} \text { Season }_{i}+\beta_{4} \text { Farm }_{i} \\
&\left.+\beta_{5} \text { s(dim } \text { dim }_{i}\right)+D_{i}+\epsilon_{i j} \\
& D_{i} \sim N\left(0, \sigma_{\text {doe }}^{2}\right), \quad \epsilon_{i j} \sim N\left(0, \sigma^{2}\right)
\end{aligned}
$$

The outcome variable $M Y_{i j}$ is the milk yield (in litres) of the $i^{t h}$ doe on the $j^{t h}$ day of lactation. Daily volume of milk produced was a function of an intercept term $\beta_{0}$ and regression coefficients $\beta_{1} \ldots \beta_{5}$ representing the effect of the 3-level categorical variable $C$. burnetii qPCR com 1 status, (described above), parity of each doe at the time of kidding (first, second, third, and fourth parity or greater), kidding season in which the doe kidded (March to April, June to July, September to October and November to December), farm ('A', 'B' and 'C') representing which of the three farms a doe was located for the duration of her lactation and days in milk (an integer ranging from 1 to up to 305), respectively. The normally-distributed random effect for each doe is represented by the term $D_{i}$ and $\epsilon_{i j}$ is the residual error (assumed to be independent and following a Normal distribution).

\section{Impact of qPCR status on somatic cell counts}

Individual SCC records were available for 401 of the goats sampled (one test per goat). Following the same methodology described in "Impact of qPCR status on daily milk yields" section, does were grouped as qPCR-positive high $(n=11)$, qPCR-positive low $(n=53)$, and qPCR-negative ( $n=337)$. To compare SCCs among the three C. burnetii qPCR com 1 status groups a multiple linear regression model was developed. SCCs were transformed to a log (natural) scale to meet normality assumptions. The variables parity, kidding season, milk yield on the day of the test (available in the database aforementioned), days in milk and farm were included as fixed effect terms to account for their potentially confounding effect on SCCs. The final model was of the form:

$$
\begin{aligned}
& \text { LogSCC } i= \beta_{0}+\beta_{1} \text { Status }_{i}+\beta_{2} \text { Parity }_{i}+\beta_{3} \text { Season }_{i} \\
&+\beta_{4} \text { Yield }_{i}+\beta_{5} \text { Farm }_{i}+\beta_{5} \operatorname{dim}_{i}+\epsilon_{i} \\
& \epsilon_{i} \sim N\left(0, \sigma^{2}\right)
\end{aligned}
$$

The outcome variable $\operatorname{LogSCC}{ }_{i}$ is the natural $\log$ SCC for the $i^{\text {th }}$ doe. The log transformed SCCs were a function of an intercept term $\beta_{0}$ and regression coefficients $\beta_{1} \ldots \beta_{5}$ representing the effect of the 3-level categorical variable C. burnetii qPCR com 1 status, (described above), parity of each doe at the time of kidding (first, second, third, and fourth parity or greater), the season in which the doe kidded (March to April, June to July, September to October and November to December), farm ('A', 'B' and 'C'), milk volume produced on the day of the SCC test and days in milk at the time of SCC test. Finally, $\epsilon_{i j}$ represents the residual error term (assumed to be independent and to follow a Normal distribution).

For both regression models, all explanatory variables were forced into the model irrespective of their statistical significance on the basis that they were considered a priori to be potential confounders of the association of interest. Frequency histograms of the residuals and plots 
of the residuals versus predicted values were developed to check that the assumptions of normality and homogeneity of variance had been met. The observed data was superimposed over a line plot of model predictions to visually assess model fit. Significance level was set at $\alpha=0.05$. Statistical analyses were carried out using $\mathrm{R}$ version 3.4 .3 [51] and packages 'gamm4' [52], 'Ime4' [53] and 'epiR' [54].

\section{Abbreviations}

AIC: Akaike information criterion; AR1: First order autoregressive (covariance); Cl: Confidence interval; CFT: Complement fixation test; Ct: Cycle threshold; DNA: Deoxyribonucleic acid; GE: Genome equivalents; IFA: Immunofluorescence assay; IgG: Immunoglobulin G; PABAK: Prevalence-adjusted and bias-adjusted kappa; qPCR: Quantitative polymerase chain reaction; SCC: Somatic cell count; SE: standard error

\section{Acknowledgements}

We would like to acknowledge laboratory support from the Australian Rickettsial Reference Laboratory as well as support from staff of the affected farm. The authors have no conflicts of interest to declare.

\section{Funding}

The Taking the $\mathrm{Q}$ (query) out of $\mathrm{Q}$ Fever project is supported by funding from the Australian Government Department of Agriculture and Water Resources as part of its Rural R\&D for profit programme (RnD4Profit-15-02-008). Simon Firestone is supported by an Australian Research Council Discovery Early Career Researcher Award (DE160100477).

\section{Availability of data and materials}

The datasets used and/or analysed during the current study are available from the corresponding author on reasonable request.

\section{Authors' contributions}

MAS, SMF, GV, AC, AWNC and JTC were involved in the study design and interpretation of results. MM, TT and JTC were involved in the sampling. AWNC provided on-farm logistic support. GV advised on laboratory work. MAS and SMF advised on data analysis. All authors participated in drafting, revising and reviewing the manuscript. JTC prepared the final version for submission. All authors read and approved the final manuscript.

\section{Ethics approval and consent to participate}

All animal sampling was conducted with the approval of the University of Melbourne Animal Ethics Committee, Application Number 1413118.

\section{Consent for publication}

Not applicable.

\section{Competing interests}

The authors declare that they have no competing interests.

\section{Publisher's Note}

Springer Nature remains neutral with regard to jurisdictional claims in published maps and institutional affiliations.

\footnotetext{
Author details

${ }^{1}$ Asia-Pacific Centre for Animal Health, Faculty of Veterinary and Agricultural Sciences, The University of Melbourne, Corner Park Drive and Flemington Road, 3010 Parkville Victoria, Australia. ${ }^{2}$ Instituto de Investigación Animal del Chaco Semiárido, INTA, Leales, 4113 Tucumán, Argentina. ${ }^{3}$ Australian Rickettsial Reference Laboratory, Ballerine Street, 3220 Geelong Victoria, Australia. ${ }^{4}$ Meredith Dairy, Camerons Road, 3333 Meredith Victoria, Australia.
}

Received: 23 August 2018 Accepted: 23 October 2018

Published online: 20 November 2018

\section{References}

1. Maurin M, Raoult D. Q fever. Clin Microbiol Rev. 1999;12:518-53.
2. Guatteo R, Seegers $H$, Taurel A-F, Joly A, Beaudeau F. Prevalence of Coxiella burnetii infection in domestic ruminants: A critical review. Vet Microbiol. 2011;149:1-16.

3. Million M, Raoult D. No such thing as chronic Q fever. Emerg Infect Dis. 2017;23:856-7.

4. Lennette EH, ClarkWH, Dean BH. Sheep and goats in the epidemiology of Q fever in northern California. Am J Trop Med Hyg. 1949;29:527-41.

5. Hatchette T, Hudson R, Schlech W, Campbell N, Hatchette J, Ratnam S, Raoult D, Donovan C, Marrie T. Goat-associated Q fever: A new disease in Newfoundland. Emerg Infect Dis. 2001;7:413-9.

6. Dijkstra F, van der Hoek W, Wijers N, Schimmer B, Rietveld A, Wijkmans CJ, Vellema P, Schneeberger PM. The 2007-2010 Q fever epidemic in The Netherlands: Characteristics of notified acute $Q$ fever patients and the association with dairy goat farming. FEMS Immunol Med Microbiol. 2012;64:3-12

7. Agerholm J. Coxiella burnetii associated reproductive disorders in domestic animals — a critical review. Acta Vet Scand. 2013;55:13.

8. Barlow J, Rauch B, Welcome F, Kim SG, Dubovi E, Schukken Y. Association between Coxiella burnetii shedding in milk and subclinical mastitis in dairy cattle. Vet Res. 2008;39(3):23.

9. Freick M, Enbergs H, Walraph J, Diller R, Weber J, Konrath A. Coxiella burnetii: Serological reactions and bacterial shedding in primiparous dairy cows in an endemically infected herd-impact on milk yield and fertility. Reprod Domest Anim. 2017;52(1):160-9.

10. Sánchez J, Souriau A, Buendía AJ, Arricau-Bouvery N, Martínez CM Salinas J, Rodolakis A, Navarro JA. Experimental Coxiella burnetii infection in pregnant goats: a histopathological and immunohistochemical study. J Comp Pathol. 2006;135:108-15.

11. Muleme M, Stenos J, Vincent G, Wilks C, Devlin J, Campbell A, Cameron A, Stevenson M, Graves S, Firestone S. Peripartum dynamics of Coxiella burnetii infections in intensively managed dairy goats associated with a Q fever outbreak in Australia. Prev Vet Med. 2017;139:58-66.

12. Bouvery NA, Souriau A, Lechopier P, Rodolakis A. Experimental Coxiella burnetii infection in pregnant goats: Excretion routes. Vet Res. 2003;34: 423-33.

13. Rodolakis A, Berri M, Héchard C, Caudron C, Souriau A, Bodier CC, Blanchard B, Camuset P, Devillechaise P, Natorp JC, Vadet JP, Arricau-Bouvery N. Comparison of Coxiella burnetii shedding in milk of dairy bovine, caprine, and ovine herds. J Dairy Sci. 2007;90(12):5352-60.

14. Sting R, Molz K, Philipp W, Bothe F, Runge M, Ganter M. Quantitative real-time $P C R$ and phase specific serology are mutually supportive in $Q$ fever diagnostics in goats. Vet Microbiol. 2013;167:600-8.

15. Roest HIJ, Bossers A, van Zijderveld FG, Rebel JM. Clinical microbiology of Coxiella burnetii and relevant aspects for the diagnosis and control of the zoonotic disease Q fever. Vet Q. 2013;(3):148-160.

16. Berri M, Laroucau K, Rodolakis A. The detection of Coxiella burnetii from ovine genital swabs, milk and fecal samples by the use of a single touchdown polymerase chain reaction. Vet Microbiol. 2000;72:285-93.

17. Roest HIJ, van Gelderen B, Dinkla A, Frangoulidis D, van Zijderveld F, Rebel J, van Keulen L. Q fever in pregnant goats: pathogenesis and excretion of Coxiella burnetii. PLoS ONE. 2012;7(11):1-14.

18. Kim SG, Kim EH, Lafferty CJ, Dubovi E. Coxiella burnetii in bulk tank milk samples, United States. Emerg Infect Dis. 2005;11(4):619-21.

19. van den Brom R, van Engelen E, Luttikholt S, Moll L, van Maanen K, Vellema P. Coxiella burnetii in bulk tank milk samples from dairy goat and dairy sheep farms in The Netherlands in 2008. Vet Rec. 2012;170:310.

20. Boarbi S, Mori M, Rousset E, Sidi-Boumedine K, Van Esbroeck M, Fretin D. Prevalence and molecular typing of Coxiella burnetii in bulk tank milk in Belgian dairy goats, 2009 - 2013. Vet Microbiol. 2014;170:117-24.

21. Jones RM, Twomey DF, Hannon S, Errington J, Pritchard GC, Sawyer J. Detection of Coxiella burnetii in placenta and abortion samples from British ruminants using real-time PCR. Vet Rec. 2010;167:965-7.

22. Klee SR, Tyczka J, Ellerbrok H, Franz T, Linke S, Baljer G, Appel B. Highly sensitive real-time $P C R$ for specific detection and quantification of Coxiella burnetii. BMC Microbiol. 2006;6:2.

23. Fenollar F, Raoult D. Molecular diagnosis of bloodstream infections caused by non-cultivable bacteria. Int J Antimicrob Agents. 2007;30:7-15.

24. Jones RM, Hertwig S, Pitman J, Vipond R, Aspán A, Bölske G, McCaughey C, McKenna JP, van Rotterdam BJ, de Bruin A, Ruuls R, Buijs $\mathrm{R}$, Roest H-J, Sawyer J. Interlaboratory comparison of real-time 
polymerase chain reaction methods to detect Coxiella burnetii, the causative agent of Q fever. J Vet Diagn Investig. 2011;23:108-11.

25. Muleme M, Stenos J, Vincent G, Campbell A, Graves S, Warner S, Devlin JM, Nguyen C, Stevenson MA, Wilks CR, Firestone SM. Bayesian validation of the indirect immunofluorescence assay and its superiority to the enzyme-linked immunosorbent assay and the complement fixation test for detecting antibodies against Coxiella burnetii in goat serum. Clin Vaccine Immunol. 2016;23:507-14.

26. Gidding HF, Wallace C, Lawrence GL, McIntyre PB. Australia's national Q fever vaccination program. Vaccine. 2009;27:2037-41.

27. Anonymous: National Notifiable Diseases Surveillance System, Australian Government Department of Health. Accessed: 2018-05-02. http://www9. health.gov.au/cda/source/rpt_4_sel.cfm.

28. Bond K, Franklin L, Sutton B, Stevenson M, Firestone S. Review of 20 years of human acute $\mathrm{Q}$ fever notifications in Victoria, 1994-2013. Aust Vet J. 2018:96:223-30.

29. Bond KA, Vincent $G$, Wilks $C R$, Franklin $L$, Sutton $B$, Stenos J, Cowan $R$, Lim K, Athan E, Harris O, Macfarlane-Berry L, Segal Y, Firestone SM. One Health approach to controlling a $Q$ fever outbreak on an Australian goat farm. Epidemiol Infect. 2016;144:1129-41.

30. Hatchette T, Campbell N, Hudson R, Raoult D, Marrie TJ. Natural history of Q fever in goats. Vector-Borne Zoonotic Dis. 2003;3:11-15.

31. Berri M, Rousset E, Champion JL, Russo P, Rodolakis A. Goats may experience reproductive failures and shed Coxiella burnetii at two successive parturitions after a Q fever infection. Res Vet Sci. 2007;83:47-52.

32. Astobiza I, Barandika JF, Ruiz-Fons F, Hurtado A, Povedano I, Juste RA, García-Pérez AL. Coxiella burnetii shedding and environmental contamination at lambing in two highly naturally-infected dairy sheep flocks after vaccination. Res Vet Sci. 2011;91:58-63.

33. Piñero A, Ruiz-Fons F, Hurtado A, Barandika JF, Atxaerandio R, García-Pérez AL. Changes in the dynamics of Coxiella burnetii infection in dairy cattle: An approach to match field data with the epidemiological cycle of C. burnetii in endemic herds. J Dairy Sci. 2014;97:2718-30.

34. Lang GH. Coxiellosis (q fever) in animals. In: Marrie TJ, editor. Q Fever, the Disease. Boca Raton: CRC Press; 1990. p. 23-48. Chap. 2.

35. EFSA Panel on Animal Health and Welfare (AHAW): Scientific opinion on Q fever. EFSA J. 2010;8(5):1-114.

36. Astobiza I, Barandika JF, Hurtado A, Juste RA, García-Pérez AL. Kinetics ofCoxiella burnetii excretion in a commercial dairy sheep flock after treatment with oxytetracycline. Vet J. 2010;184(2):172-5.

37. Bontje DM, Backer JA, Hogerwerf L, Roest HIJ, van Roermund HJW. Analysis of $\mathrm{Q}$ fever in Dutch dairy goat herds and assessment of control measures by means of a transmission model. Prev Vet Med. 2016;123: 71-89.

38. Porten K, Rissland J, Tigges A, Broll S, Hopp W, Lunemann M, Van Treeck U, Kimming P, Brockmann SO, Wagner-Wiening C, Hellenbrand W, Buchholz U. A super-spreading ewe infects hundreds with Q fever at a farmers' market in Germany. BMC Infect Dis. 2006;6:1-13.

39. Capparelli R, Parlato M, lannaccone M, Roperto S, Marabelli R, Roperto F, lannelli D. Heterogeneous shedding of Brucella abortus in milk and its effect on the control of animal brucellosis. J Appl Microbiol. 2009;106: 2041-7.

40. Omisakin F, MacRae M, Ogden ID, Strachan NJC. Concentration and prevalence of Escherichia coli $\mathrm{O} 157$ in cattle feces at slaughter. Appl Environ Microbiol. 2003;69:2444-7.

41. de Cremoux R, Rousset E, Touratier A, Audusseau G, Nicollet P, Ribaud D, David V, Le Pape M. Coxiella burnetii vaginal shedding and antibody responses in dairy goat herds in a context of clinical $\mathrm{Q}$ fever outbreaks. FEMS Immunol Med Microbiol. 2012;64(1):120-2.

42. Berri $M$, Rousset $E$, Hechard $C$, Champion JL, Dufour $P$, Russo $P$, Rodolakis A. Progression of q fever and Coxiella burnetii shedding in milk after an outbreak of enzootic abortion in a goat herd. Vet Rec. 2005;156(17):548-9.

43. Hazlett MJ, McDowall R, DeLay J, Stalker M, McEwen B, van Dreumel T, Spinato M, Binnington B, Slavic D, Carman S, Cai HY. A prospective study of sheep and goat abortion using real-time polymerase chain reaction and cut point estimation shows Coxiella burnetii and Chlamydophila abortus infection concurrently with other major pathogens. J Vet Diagn Investig. 2013;25(3):359-68.
44. Rousset E, Berri M, Durand B, Dufour P, Prigent M, Delcroix T, Touratier A, Rodolakis A. Coxiella burnetii shedding routes and antibody response after outbreaks of $\mathrm{Q}$ fever-induced abortion in dairy goat herds. Appl Environ Microbiol. 2009;75:428-33.

45. Guatteo R, Joly A, Beaudeau F. Shedding and serological patterns of dairy cows following abortions associated with Coxiella burnetii DNA detection. Vet Microbiol. 2012;155:430-3.

46. Bauer AE, Hubbard KRA, Johnson AJ, Messick JB, Weng H-Y, Pogranichniy RM. A cross sectional study evaluating the prevalence of Coxiella burnetii, potential risk factors for infection, and agreement between diagnostic methods in goats in indiana. Prev Vet Med. 2016;126: $131-7$.

47. Lockhart MG, Graves SR, Banazis MJ, Fenwick SG, Stenos J.A comparison of methods for extracting DNA from Coxiella burnetii as measured by a duplex qPCR assay: DNA extraction for $C$. burnetii qPCR. Lett Appl Microbiol. 2011;52:514-20.

48. Muleme M, Campbell A, Stenos J, Devlin JM, Vincent G, Cameron A, Graves S, Wilks CR, Firestone S. A longitudinal study of serological responses to Coxiella burnetii and shedding at kidding among intensively-managed goats supports early use of vaccines. Vet Res. 2017:48(1):50.

49. Banazis MJ, Bestall AS, Reid SA, Fenwick SG. A survey of western australian sheep, cattle and kangaroos to determine the prevalence of Coxiella burnetii. Vet Microbiol. 2010;143:337-45.

50. Dohoo IR, Martin SW, Stryhn H. Veterinary Epidemiologic Research, 2nd edn. Charlottetown: VER, Incorporated; 2009.

51. R Core Team: R: A Language and Environment for Statistical Computing Vienna: R Foundation for Statistical Computing; 2017. R Foundation for Statistical Computing. https://www.R-project.org/.

52. Wood S, Scheipl F. Gamm4: Generalized Additive Mixed Models Using 'mgcv' and 'Ime4'. 2017. R package version 0.2-5. https://CRAN.R-project. org/package $=$ gamm4.

53. Bates D, Mächler M, Bolker B, Walker S. Fitting linear mixed-effects models using Ime4. J Stat Softw. 2015;67(1):1-48.

54. Stevenson M, Nunes T, Heuer C, Marshall J, Sanchez J, Thornton R, Reiczigel J, Robison-Cox J, Sebastiani P, Solymos P, Yoshida K, Jones G, Pirikahu S, Firestone S, Kyle R. epiR: Tools for the Analysis of Epidemiological Data. R package version 0.9-93. 2018.

Ready to submit your research? Choose BMC and benefit from

- fast, convenient online submission

- thorough peer review by experienced researchers in your field

- rapid publication on acceptance

- support for research data, including large and complex data types

- gold Open Access which fosters wider collaboration and increased citations

- maximum visibility for your research: over 100M website views per year

At BMC, research is always in progress.

Learn more biomedcentral.com/submissions 